\title{
A working visit to Chad's refugee camps for the people of Western Darfur
}

\author{
Nick Rose FRCPsych
}

Oxford, UK, email nick.rose276@ntlworld.com

\begin{abstract}
n 2004 at least 200000 people from Darfur in Western Sudan are thought to have died in a wave of what has been alleged to have been ethnic cleansing (Flint \& De Waal, 2008). And in April 2008 it was reported that a total of over 300000 people might have died in the (then) 5-year Darfur conflict. During the period of the alleged genocide, nearly a quarter of a million refugees (Central Intelligence Agency, 2009) crossed the nearby border into Chad, where they remain in a dozen or so camps looked after by the United Nations and international aid organisations. These camps are strung along the frontier, in remote semi-desert locations that are sustainable only with United Nations support. Many of the camps no longer take new refugees, and are in effect transplanted communities from nearby Darfur, their social and leadership structures mirroring those of the communities that were torn apart by war. Even place names have been transplanted, to suggest a kind of normality.
\end{abstract}

\section{The health system in the camps}

The case example of Abdaman is presented in Box 1 to illustrate the nature of the health system in the camps. Each camp is home to around 16000 refugees and has about 40 community health workers, who are locally trained refugees familiar with the dialects and customs of the camp population. Every health worker has a community patch and also spends time in the central health centre. This centre, usually operating from a group of simple tents or buildings at the edge of the camp, provides basic medical, maternity, and in some cases psychosocial care, together with immunisation and child nutrition clinics.

In those camps with a psychosocial programme (at present about half of them), two community health workers are selected and given training in the detection and management of people who have serious mental health problems. It was one of these more specialised health workers who engaged with Abdaman's family after being alerted by the local community health worker.

The psychiatric team for a camp consists of two psychosocial community health workers, supervised by a Chadian

In late 2009 Dr Nick Rose worked as a consultant for the International Medical Corps (IMC) in Eastern Chad. Since February 2010 he has been working for IMC based in Port-au-Prince, Haiti. The views expressed are those of the author, and do not necessarily represent those of IMC. Dr Lynne Jones of IMC instigated the original mental health programme in Chad.

\section{Box 1 Abdaman's story}

Abdaman was recruited into a local rebel army as a teenager, and had witnessed bad things. At 19 he returned to the family compound in Sudan's Western Darfur apparently traumatised. His mother took him to traditional healers, but his night terrors, paranoid ideas and disturbed behaviour persisted. In early 2005 his family crossed the nearby border into Chad, escaping the organised slaughter of their people by the Janjaweed militia. Abdaman's father and two brothers were never seen again.

In Chad, the family was taken to one of the international refugee camps, in a zone with other families from their part of Darfur. Their new community included a familiar local leader, as well as fellow farmers and traders who had survived the violence. Further expensive visits to traditional healers failed to help Abdaman, who for much of the time was in chains. His mother had taken the decision to confine him to the small mud compound that was now the family home to stop him disappearing into the desert. In mid-2009, one of the refugee community health workers covering the zone in which the family lived got to hear about Abdaman, and spoke to the community leader. A visit from a more specialised psychosocial community health worker (also a refugee) was arranged. He thought that Abdaman was suffering from a post-traumatic state and sought the advice of his supervisor, a Chadian-trained psychiatric nurse. A joint home visit by the nurse and a visiting psychiatrist confirmed a diagnosis of paranoid schizophrenia, perhaps triggered by exposure to trauma. Depot medication was started, and after a month the mother felt able to unlock her son's chains. It is hoped that Abdaman will benefit from attending an activity programme for vulnerable young men.

psychiatric nurse and, when available, a visiting psychiatrist. Psychiatrists are hard to recruit, so, as in most sub-Saharan countries, nurses routinely assess and provide the care, supported where needed by general medical officers. As well as running twice-weekly clinics and doing home visits, the team also runs groups for mothers and for children, and plans further groups for vulnerable young men and for carers.

\section{Whom does the psychiatric team see?}

The clinical activity figures for one of the typical camps during the most recent year are summarised in Table 1 . As can be seen, despite being a clinic for refugees, a large number of local Chadian villagers were assessed, among them a high proportion of people with epilepsy. These were mainly children, often brought on long journeys by their parents. 
Table 1 Numbers of new cases presenting at a typical refugee camp, January 2008 to January 2009

$\begin{array}{lcc}\text { Diagnosis } & \begin{array}{l}\text { Refugees } \\ \text { in the camp } \\ (n=60)\end{array} & \begin{array}{c}\text { Chadian } \\ \text { villagers } \\ (n=103)\end{array} \\ \text { Dementia } & 0 & 3 \\ \text { Epilepsy } & 13 & 55 \\ \text { Intellectual disability } & 1 & 1 \\ \text { Bipolar disorder } & 9 & 8 \\ \text { Schizophrenia } & 3 & 10 \\ \text { Substance misuse } & 0 & 4 \\ \text { Depression } & 8 & 12 \\ \text { Somatoform disorder } & 7 & 4 \\ \text { Post-traumatic stress disorder } & 8 & 1 \\ \text { Anxiety } & 11 & 5\end{array}$

Camp population approximately 16000 . Village population hard to estimate but probably in excess of 20000 .

Table 2 All cases seen in September 2009, Guereda camp

$\begin{array}{lcc}\text { Diagnosis } & \begin{array}{l}\text { New } \\ \text { cases } \\ (n=21)\end{array} & \begin{array}{l}\text { Follow- } \\ \text { up cases } \\ (n=335)\end{array} \\ \text { Dementia } & 0 & 8 \\ \text { Epilepsy } & 10 & 197 \\ \text { Attention-deficit hyperactivity disorder } & 0 & 8 \\ \text { Bipolar disorder } & 5 & 4 \\ \text { Schizophrenia } & 5 & 60 \\ \text { Substance misuse } & 0 & 0 \\ \text { Depression } & 0 & 56 \\ \text { Somatoform disorder } & 1 & 0 \\ \text { Post-traumatic stress disorder } & 0 & 2 \\ \text { Anxiety } & 0 & 0\end{array}$

Camp population approximately 16000 .

The relatively high numbers may in part reflect poor obstetric care in the more remote communities, where there also seemed to be high levels of maternal and infant mortality, probably caused by poor nutrition and lack of antenatal care. The higher levels of post-traumatic stress disorder among the refugee population reflect the violent circumstances that resulted in the exodus from Darfur. In addition, 30 cases of sexual and gender-based violence were seen during the year, almost all involving female refugees.

Table 2 lists all cases seen in a typical 'snapshot' month at another camp, where over $90 \%$ of follow-up consultations were for patients who had epilepsy, schizophrenia or depression.

\section{What were the dilemmas faced in Chad?}

Abdaman's case posed some tricky dilemmas for aid workers. Perhaps the most challenging was whether it was right to keep him in chains. But with virtually no resources or legal framework to draw on, was there a sufficiently safe alternative? In this case the family took responsibility for the care of their son, and worked with the team to make sure that medication was taken regularly, and that he was humanely looked after. They also cooperated with regular reviews of his progress, with the aim of minimising the time he spent in chains - a pragmatic approach that, given Abdaman's lack of capacity, traded his right to liberty with his need to be kept safe and receive medical help.

In these resource-poor circumstances, medical aid organisations have to work in ways that are consistent with universal human rights yet do not undermine local resourcefulness. This is particularly important since aid organisations are usually unable to provide safe alternatives to family care. So in practice, it is important to identify people with mental illness cared for in chains as early as possible, and then to have an agreed approach for working with the families and community members concerned. The focus is on urgent treatment provision, regular monitoring, making sure that the patient's living circumstances are as minimally restrictive as possible, and checking that abuse is not occurring. Public education and the sensitisation of local leaders are also important.

A further dilemma arises from the fact that impoverished as the refugees like Abdaman are, local Chadian villagers are often worse off. This is borne out by the particularly high levels of maternal mortality and childhood malnutrition among villagers. The dilemma for the medical aid organisation, of course, is whether to treat refugees only, for whose care funding was raised, or to treat everyone, including the region's non-refugee population. Ethically, the only answer is to treat everyone equitably. And so villagers travel for up to 2 days across the desert to receive treatment. In one particular camp clinic, for example, 63\% of attendees over a 1-year period were villagers (see Table 1).

\section{What seemed to work well?}

Employing and training refugees as health workers seemed to benefit everyone. Patients had helpers who spoke their dialect, understood their beliefs and customs, and lived nearby. The employed refugees had a job and a greater sense of empowerment. And the aid organisation could maximise the effect of the relatively small number of skilled outside staff it employed. This is particularly important in a country with few mental health staff (see below). Another effective way of reaching people in need of services was to train community and religious leaders, teachers and general health workers in mental health awareness, a strategy now well established in post-trauma situations (Danvers et al, 2006; Makhdum \& Javed, 2006).

In terms of developing the skills of mental health workers, what seemed to work best was to train people in their workplace as much as possible, usually by giving them feedback on directly observed clinical, liaison and public health work. This is expensive in terms of the skilled workforce, but was achieved across a span of five large refugee camps by one psychiatrist providing on-the-job training in each camp at least once every 2 weeks, with access to telephone advice at any time. The long-term plan is to replace the international psychiatrist with a local one, but this is unlikely to happen in the foreseeable future because of the shortage of Chadian psychiatrists, combined with the challenges of working in remote, resource-poor settings. So for the moment, the psychiatrist is provided on a long-term basis by an international medical aid organisation. 


\section{Can this model be scaled up?}

The model described above depends on one supervising psychiatrist covering up to six refugee camps together with the surrounding villages, equivalent to a general population of about 100000 . Each camp has clinics and basic therapeutic activities run by a specialist community mental health nurse supported by trained volunteers and other health workers. But the important question in relation to sustainability is whether, without international input, such a model can be replicated across all refugee camps in Chad, or be scaled up to run nationally. Sadly, the answer is probably not, mainly because of the lack of available local psychiatrists, although specialist mental health nurses are also in short supply. The Mental Health Atlas published by the World Health Organization (2005) describes Chad as having no mental health policy, and 0.01 psychiatrists per 100000 people. The country has a population of 10.3 million. A more recent estimate of psychiatrists in a number of other African counties (Jenkins et al, 2010) estimates an average of 0.33 per 100000 people, but does not include Chad. It is hard to know how accurate these figures are, but they confirm my impression that, compared with many other African countries, Chad is particularly short of trained mental health staff. So, without the prospect of local recruitment, the existing programme is dependent on international aid for psychiatrist input and, given the demands on donors elsewhere, this is unlikely to be scaled up in the future, and may indeed be phased out at some point.

In the long term, therefore, true sustainability of the existing programme, and further development of services across the country, could be achieved only through big institutional infrastructure projects such as supporting the Chadian government to design a funded mental health policy and strategy, and by developing national training programmes for mental health professionals.

\section{Lasting memories}

Imprinted most lastingly on my memory is the dignity with which those who have lost everything conduct themselves. This was apparent in the way families presented at clinic, squeezed on to rough benches, patiently and gracefully waiting their turn, often dressed in colours and tribal designs that echoed their rich heritage as descendants of a powerful 19th-century North African kingdom. And patients almost always attended with their family. So the strategy of keeping families and local communities together after the chaotic mass exodus from Darfur appears to have worked, thereby protecting the all-important social capital and natural resilience associated with relationships that is so crucial for mental well-being in the aftermath of trauma (Pfefferbaum, 2008)

\section{References}

Central Intelligence Agency (2009) The World Fact Book. Chad data on refugees and internally displaced persons. Available at https://www. cia.gov/library/publications/the-world-factbook/geos/cd.html (accessed September 2009).

Danvers, K., Sivayokan, S., Somasundaram D. J., et al (2006) Ten months on: qualitative assessment of psychosocial issues in northern Sri Lanka following the tsunami. International Psychiatry, 3(3), 5-8.

Flint, J. \& De Waal, A. (2008) Darfur: A New History of a Long War. Zed Books.

Jenkins, R., Gureje, O., Mullen, P., et al (2010) International migration of psychiatrists. PLOS One. Available at http://dx.plos.org/10.1371/ journal.pone.0009049 (accessed September 2009).

Makhdum, M. A. \& Javed, A. (2006) Earthquake in Pakistan and Kashmir: suggested plan for psychological trauma relief work. International Psychiatry, 3(1), 16-18.

Pfefferbaum, R. L. (2008) Factors in the development of community resilience to disasters. In Intervention and Resilience After Mass Trauma (eds M. Blumenfield \& R. J. Ursano), pp. 49-68. Cambridge University Press.

World Health Organization (2005) Chad. In Mental Health Atlas, pp. 127-128. WHO.

\section{Getting your paper published}

\section{Patricia Casey}

Editor, The Psychiatrist, and Professor of Psychiatry, Mater Misericordiae University Hospital, Dublin, Ireland, email apsych@mater.ie

단 mbarking on a research project is always exciting, although a large number are not completed. One study of pharmacotherapy projects submitted to a research ethics committee found that after 5 years more than a quarter had not been completed and almost a sixth were considered unpublishable (Winther \& Hole, 1997).

Achieving publication is the aim of most doctors. The primary motivation for this varies from a wish to enhance job prospects to boosting one's ego and a desire to see one's name in print. The most noble, of course, is a desire to spread knowledge and contribute to the science of our specialty.

The proportion of submitted papers that ultimately succeed in achieving publication varies greatly; journals with a high impact factor have the lowest yield. For The Psychiatrist, the proportion of submitted papers that are published is around $50 \%$, well above the $16.6 \%$ identified in one study of eight high-impact English-language journals (although only five replied to the study questionnaire) (Singh, 2006), a figure that fell to only $4.4 \%$ when papers from low- and 